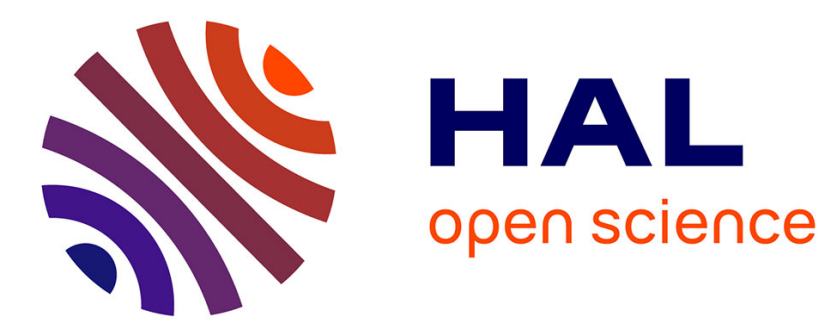

\title{
Crystalline arrangement of some disc like compounds
}

\author{
M. Cotrait, P. Marsau, C. Destrade, J. Malthete
}

\section{To cite this version:}

M. Cotrait, P. Marsau, C. Destrade, J. Malthete. Crystalline arrangement of some disc like compounds. Journal de Physique Lettres, 1979, 40 (19), pp.519-522. 10.1051/jphyslet:019790040019051900 jpa00231678

\section{HAL Id: jpa-00231678 https://hal.science/jpa-00231678}

Submitted on 1 Jan 1979

HAL is a multi-disciplinary open access archive for the deposit and dissemination of scientific research documents, whether they are published or not. The documents may come from teaching and research institutions in France or abroad, or from public or private research centers.
L'archive ouverte pluridisciplinaire HAL, est destinée au dépôt et à la diffusion de documents scientifiques de niveau recherche, publiés ou non, émanant des établissements d'enseignement et de recherche français ou étrangers, des laboratoires publics ou privés. 


\title{
Crystalline arrangement of some disc like compounds
}

\author{
M. Cotrait, P. Marsau \\ Laboratoire de Cristallographie et de Physique Cristalline, Université de Bordeaux I, \\ 351, cours de la Libération, 33405 Talence, France \\ C. Destrade \\ Centre de Recherche Paul Pascal, Domaine Universitaire, 33405 Talence, France
}

and J. Malthete

Laboratoire de Chimie Organique des Hormones, Collège de France, 11, place M.-Berthelot, 75231 Paris Cedex 05, France

(Reçu le 13 juin 1979, accepté le 17 août 1979)

\begin{abstract}
Résumé. - Trois esters du triphénylène, molécules de type discoïde appartenant à une série de composés, dont certains présentent une phase mésomorphe thermotrope nouvelle, ont été étudiés par diffraction des rayons $\mathbf{X}$. La structure d'un de ces esters a été établie. Les molécules s'associent en donnant des paires, leurs noyaux triphénylène étant parallèles et à 3,43 Å l'un de l'autre. Ces dimères forment des colonnes arrangées suivant un réseau hexagonal.
\end{abstract}

\begin{abstract}
Three triphenylene esters, disc-like molecules, belonging to a series of compounds, some of which show a new mesomorphic and thermotropic phase have been studied by X-ray diffraction. The crystal structure of one of these esters has been established. Molecules are associated in pairs with their triphenylene cores parallel and $3.43 \AA$. These dimers give columns arranged in hexagonal lattice.
\end{abstract}

It is now well established that, in most cases, there is a well defined relationship between molecular arrangement in the crystal and in the mesomorphic phase of a thermotropic liquid crystal [1-3]. Moreover, in some cases, complementary information on the mesomorphic order itself can be deduced from the arrangement in the solid state [4-6]. Any way, a comparative study of both phases by X-ray diffraction is highly informative. In other respects the knowledge of molecular geometry and interactions allows us to perform energy calculations which may provide information when going from the crystal to the mesophase [7, 8].

The numerous results obtained in recent years were concerned only with liquid crystals of rod-like molecules showing nematic, smectic or cholesteric phases. Recently, it has been shown that disc-like molecules are able to give a thermotropic and mesomorphic phase $[9,10,11]$, which, is in fact, a new state of matter. In this phase, molecules are thought to be stacked in infinite columns lying parallel to each other [9-12].
Two families of mesogenic disc-like molecules are currently known :

- hexasubstituted benzene derivatives : benzene$n$-alkanoates [9],

- hexasubstituted triphenylene derivatives with the general formula :

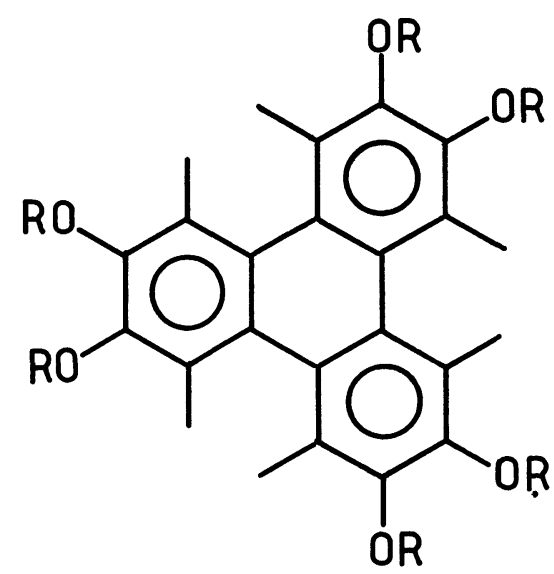


Three homologous series have been synthesized in our laboratory :

with

$$
\begin{aligned}
& \mathrm{R}=\mathrm{C}_{n} \mathrm{H}_{2 n+1} \quad \text { (hexaethers) [10] } \\
& \mathrm{R}=\mathrm{COO}-\mathrm{C}_{n} \mathrm{H}_{2 n+1} \quad \text { (hexaesters) [10] } \\
& \mathrm{R}=\mathrm{CO}-\mathrm{OC}_{n} \mathrm{H}_{2 n+1} \quad \text { (hexabenzoates) [13] }
\end{aligned}
$$

In addition we have shown that some hexaesters present a rather new mesomorphic polymorphism [12].

For the preceding reasons we were convinced of the interest in determining the crystal structure of some of these compounds. The hexaesters appeared especially interesting because the molecules cannot be planar for steric hindrance reasons. At the present time the derivatives with aliphatic chains $\mathrm{R}^{\prime}=\mathrm{C}_{3} \mathrm{H}_{7}$, $\mathrm{C}_{4} \mathrm{H}_{9}$ and $\mathrm{C}_{5} \mathrm{H}_{11}$ have been crystallized and their crystal structure determined.

The three molecules studied will be designated here as Disco 3, Disco 4 and Disco 5 respectively for the propyl, butyl and pentyl derivatives.

General crystallographic data. - The three compounds have been crystallized from methanolic solutions as rhombohedral prisms. Crystal parameters have been refined from the angular setting of a dozen reflexions measured with a CAD 4 Enraf Nonius diffractometer.

$$
\begin{aligned}
& \text { 1. Disco 3. }-\mathrm{C}_{42} \mathrm{H}_{48} \mathrm{O}_{12} ; M=744 . \\
& a=b=18.85 \begin{array}{l}
\text { (1), } \quad c=41.13 \quad \text { (2) } \AA, \\
\gamma=120^{\circ} .
\end{array}
\end{aligned}
$$

Assuming the presence of twelve molecules in the cell, the calculated density $d_{\mathrm{c}}$ is equal to 1.17 , in agreement with that of other mesomorphic compounds [14]. Reflexions are observed only for the following conditions :

$$
\begin{aligned}
& \text { hkil }:-h+k+l=3 n \\
& \text { hh } 2 \bar{h} l:(l=3 n) \\
& h \bar{h} 0 l:(-h+l=3 n) ; \quad l=3 n .
\end{aligned}
$$

These are consistent with both the $\mathrm{R} 3 c(Z=6)$ and $\mathrm{R} \overline{3} c(Z=36)$ space group, with, in the present case, 2 and $1 / 3$ of the molecule per asymmetric unit respectively. The statistical distribution of diffracted intensities is a hypercentric one according to Wilson, so the centrosymmetric $\mathbf{R} \overline{3} c$ space group is favoured.

2. DisCO 4. $-\mathrm{C}_{48} \mathrm{H}_{60} \mathrm{O}_{12} ; M=828$.

$$
\begin{array}{lll}
a=33.69 & (2), \quad b=20.60 \quad(1), \\
c=53.57 & \text { (3) } \AA ; & \beta=128.58 \quad(5)^{\circ} .
\end{array}
$$

The diffracted intensities show the space group to be $\mathrm{C} 2 / c(Z=8)$. Consequently, there should be
3 molecules per asymmetric unit ( 24 in the cell). It is possible, from the monoclinic unit cell to build another cell, a pseudo-hexagonal one with :

$$
\begin{gathered}
a^{\prime}=b^{\prime}=19.74 \quad(2), \quad c^{\prime}=41.91 \quad \text { (3) } \AA ; \\
\alpha=89.69 \quad(8), \quad \beta=89.66 \quad(8), \\
\gamma=62.58 \quad(7)^{\circ},
\end{gathered}
$$

which is very close to the hexagonal Disco 3 unit cell. The relative lengthening of Disco 4 parameters relatively to Disco 4 are close to 7.7 and $2 \%$ respectively and are directly related to the lengthening of the aliphatic chains. The question is : what is responsible for the distortion of the previous hexagonal lattice ? It is probably due to the fact that in some cases apparent symmetry increases with disorder [15] and is in agreement with the fact that thermal scattering is somewhat higher for Disco 3 than for Disco 4 .

3. DisCO 5. $-\mathrm{C}_{54} \mathrm{H}_{72} \mathrm{O}_{18} ; M=912$.

$$
\begin{aligned}
a=35.41 & \text { (2), } & b=21.58 \quad \text { (1), } \\
c=53.60 & \text { (3) } \AA ; & \gamma=128.50 \quad(5)^{\circ} .
\end{aligned}
$$

The space group is $\mathrm{C} 2 / c$ with 24 molecules in the unit cell as for Disco 4 ; the corresponding density is $d_{\mathrm{c}}=1.12$. The structure is isotypic of the preceding one ; there is an increase of $5 \%$ in the $a$ and $b$ parameters, $c$ being approximately constant.

Because of a very high thermal scattering (see later) no reflexions can be detected above $\theta=30^{\circ}$, most of them being very weak above $\theta=24^{\circ}$. Because of the very small ratio : number of reflexions/number of atoms, it appears that the Disco 3 structure will be most easily resolved.

Crystal structure of disco 3. - A rhombohedric crystal having a $0.35 \mathrm{~mm}$ edge has been used to collect data on a CAD 4 Enraf Nonius diffractometer under the following conditions :

Temperature : $293 \mathrm{~K}$; radiation : $\mathrm{CuK} \alpha$, $\lambda=1.5405 \AA$; graphite monochromator detector dimensions :

$$
\text { height }=4 \mathrm{~mm}, \quad \text { width }=(1.20+0.5 \operatorname{tg} \theta) \mathrm{mm} ;
$$

take-off angle $=5^{\circ}, \theta-\omega$ scans $; \theta_{\max }=30^{\circ} ;$ maximum counting time $=120 \mathrm{~s}$.

Two sets of independent reflexions belonging to two contiguous sextants of the reciprocal half sphere have been measured, then averaged ; 465 independent reflexions were then obtained among which 307 are greater than $3 \sigma$, most of them were rather weak.

The mean thermal scattering factor $B_{\mathrm{m}}$ is very high : about $15 \AA^{2}$ and the absolute scale factor $K g$ quite high as well, according to Wilson's method. The search of the structure by direct methods was unsuccessful because of the very limited number of observed intensities. Nevertheless, the structure could 
be resolved using symmetry evidence and the Patterson function. As there are 12 molecules instead of 36 in the unit cell for $\mathrm{R} \overline{3} c$, each molecule must lie on a threefold axis, the asymmetric unit corresponding to one third of the molecule. Consequently :

- the triphenylene cores must be parallel to the xy plane,

- there must be four molecules lying around each ternary axis in the unit cell so as to give columns along the $z$ axis,

- there are two other identical columns translated by $c / 3$ and $2 c / 3$ in the $z$ direction.

The Patterson function shows that the shortest distance in a column between two triphenylene cores is $c / 12=3.43 \AA$ and that they are related through a twofold axis parallel to $x y$ plane.

Because of the overlapping of peaks, no information could be obtained on the position of the $\mathrm{COO}-\mathrm{C}_{3} \mathrm{H}_{7}$ chains; they could be situated either, all on the same side of the aromatic core (form I), or alternatively, on each side of the core (form II). A self consistent field (SCF) calculation of the internal energy performed with the $\mathrm{CNDO} / 2$ program shows that the form II is more stable than the form I by $3.0 \mathrm{kcal}$ for the isolated molecule. Assuming that this is still true in the solid state, it was then necessary to establish the level $z$ of the molecular core (i.e. the average level for the molecule) and its orientation relative to $x$ and $y$ axis, i.e. rotation $\theta$ around the $z$ axis. Computing the reliability factor $\left(^{1}\right) R$ for each combination of $z$ and $\theta$, a rather sharp minimum appeared for $z=0.2083(z=5 c / 24)$ and $\theta=15^{\circ}$, corresponding to $R=0.38$ for the observed reflexions. These calculations were performed by assuming in the first approximation, that the $\mathrm{COOC}_{3} \mathrm{H}_{7}$ groups were perpendicular to the aromatic core.

Molecular arrangement and interactions. - The molecular arrangement in the crystal is schematically shown in figure 1 ; molecules are piled in columns forming a hexagonal lattice. The four molecules of a column are associated in pairs, the distance between their aromatic cores along $z$ being as short as $3.43 \AA$; the one between the cores of two unassociated molecules is as large as $17.13 \AA$. Neighboring columns are $10.92 \AA$ a part, when the distance between the centre of the aromatic core and the end of the fully extended side chain is about $11 \AA$, when projected onto the $x y$ plane. This implies that aliphatic chains

( $\left.{ }^{1}\right)$ The reliability factor is defined as

$$
R=\frac{\sum_{i=1}^{N}\left[K g\left|F_{0}\right|-\left|F_{\mathrm{c}}\right|\right]}{\sum_{i=1}^{N} K g\left|F_{0}\right|}
$$

where $F_{0}$ and $F_{\mathrm{c}}$ are the observed and calculated structure factors, $K g$ a scale factor, and $N$ the number of observed reflexions.

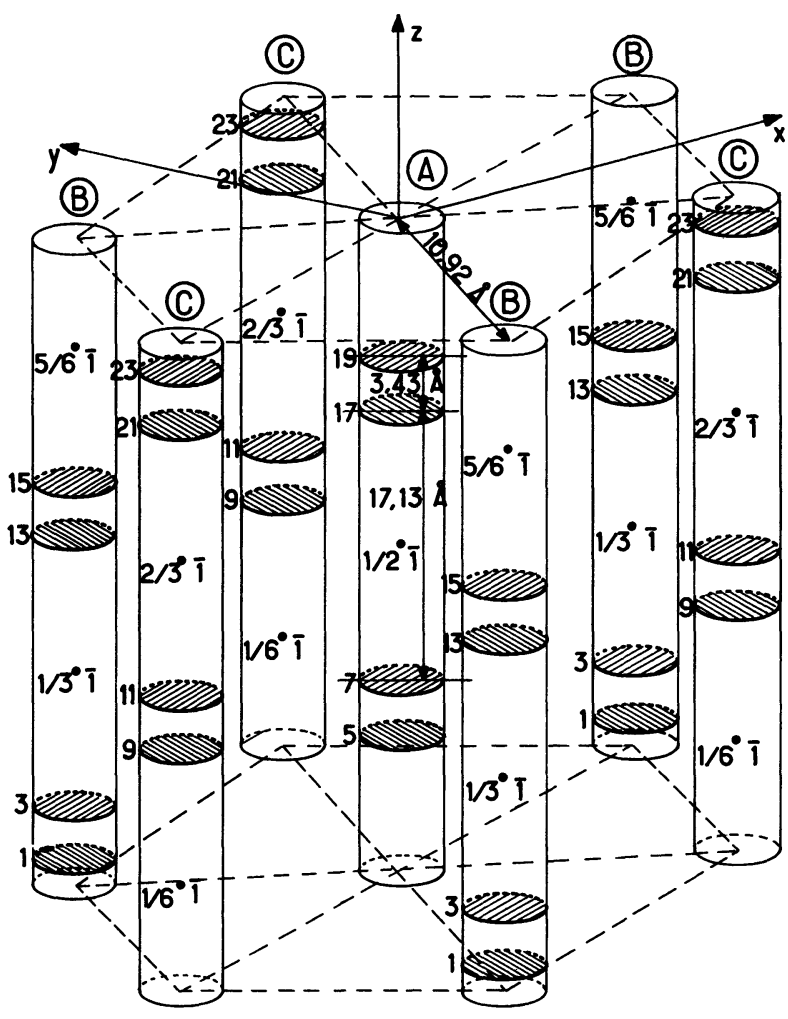

Fig. 1. - Schematic drawing of molecular arrangement in the crystal. Triphenylene cores are represented as shaded discs, with their levels given in $c / 24$ units.

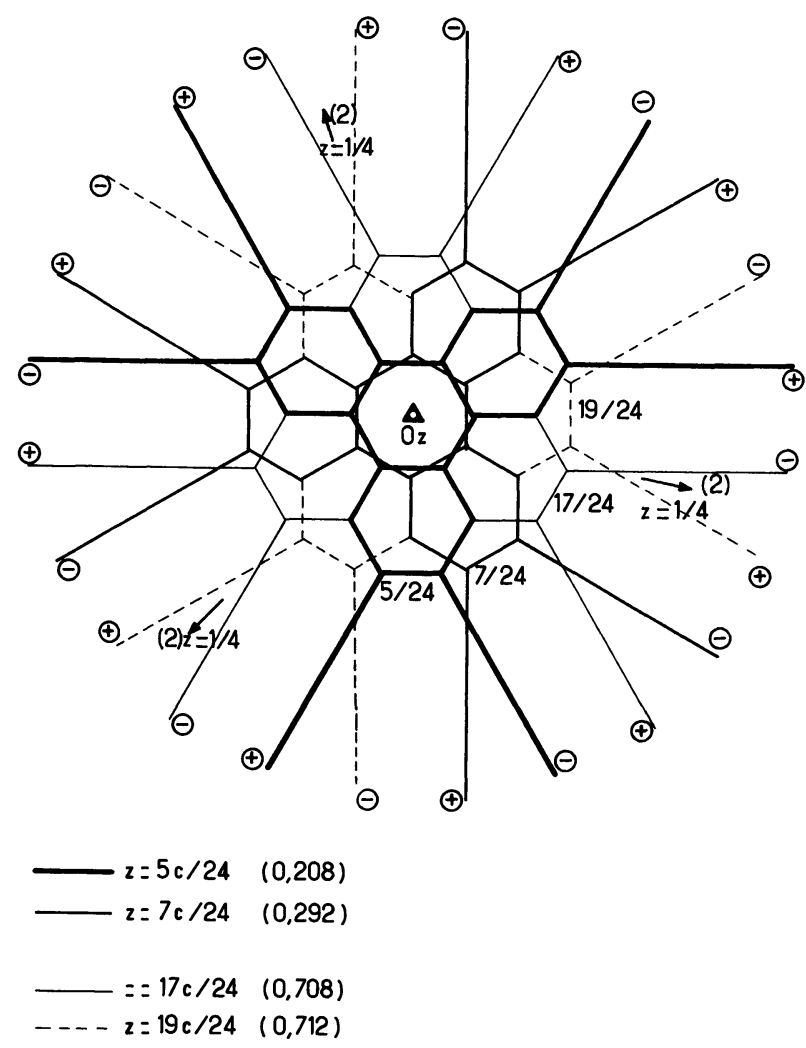

Fig. 2. - Schematic representation of molecular arrangement in a column. The levels of triphenylene core are given in $c / 24$ units; the + or - signs correspond respectively to chains going up and down. 
of one column are inserted in the free space of the neighboring columns.

Considering the structure as a whole, the triphenylene rings are distributed with an equal density at $z=c / 24,3 c / 24, \ldots, 23 c / 24$, the relative disposition of molecules in a pair is close to that shown in figure 3. The cohesion of a pair is essentially due to stacking forces between the very close aromatic rings, whose distance $d$ is slightly greater than for graphite [15], benzoperylene [16] and coronene [17] where $d$ is respectively equal to $3.35,3.38$ and $3.40 \AA$.

Moreover dipolar interactions between carboxylate groups may contribute to the stability of the pair, which probably persists in the mesophase.

Interactions between imbricated columns are very numerous and complicated to describe, they are all due to Van der Waals forces.

Conclusion. - The crystal structure of a disc-like mesogenic compound provides very interesting features on molecular arrangement : forces,

- pairs of molecules tightly bound by stacking

- arrangement of pairs in imbricated columns,

- arrangement of molecular columns to give a hexagonal lattice.

For further work, it will be necessary to know more exactly the orientation of the chains, which have a relative conformational freedom by rotation around $\mathrm{O}-\mathrm{C}$ and $\mathrm{C}-\mathrm{C}$ bonds, in order to calculate,

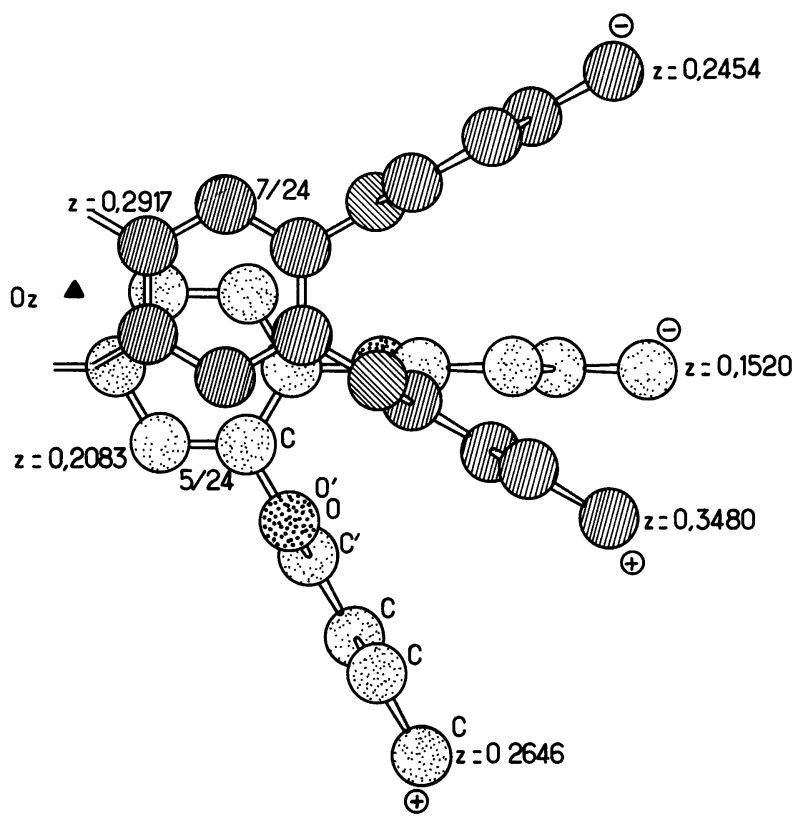

Fig. 3. - Relative disposition of one third of a pair of molecules, atomic levels $z$ are indicated for triphenylene and $\mathrm{C}$ terminal atoms.

even approximately, the cohesive forces in a pair and eventually the interactions between columns. To this end it would be desirable to obtain much bigger crystals with improved quality.

We thank Dr Pesquer for making CNDO/2 calculations.

\section{References}

[1] Krigbaum, W. R., Chatani, Y., Barber, G., Acta Crystallogr. B 26 (1977) 97.

[2] Krigbaum, W. R., Barber, G., Acta Crystallogr. B 27 (1971) 1884.

[3] Bryan, R. F., Fallon, L., J. Chem. Soc., Perkin II Trans. (1975) 1175.

[4] BRYAN, R. F., Eighth international meeting on liquid crystals, Bordeaux (1978) CP-8.

[5] Cotrait, M., C. R. Hebd. Séan. Acad. Sci. Paris, Série C 298 (1977) 547.

[6] Doucet, J., Levelut, A. M., Lambert, M., Acta Crystallogr. B 33 (1977) 1710 .

[7] Cotrait, M., Marsau, P., Pesquer, M., Acta Crystallogr. B 35 (1979) 1102.

[8] Cotrait, M., Marsau, P., Pesquer, M., Acta Crystallogr. B 35 (1979) in press.
[9] Chandrasekhar, S., Sadashiva, B. K., Suresh, K. A., Pramana. 9 (1977) 471.

[10] Destrade, C., Mondon, M. C., Malthete, J., J. Physique Colloq. 40 (1979) C3-17.

[11] Destrade, C., Mondon-Bernaud, M. C., Nguyen, H. T., Mol. Cryst. Liq. Cryst. Lett. 49 (1979) 169.

[12] Levelut, A. M., J. Physique Lett. 40 (1979) L-81.

[13] Nguyen, H. T., Destrade, C., Gasparoux, H., Phys. Lett. A (1979) in press.

[14] Cotrait, M., Destrade, C., Gasparoux, H., Mol. Cryst. Liq. Cryst. 39 (1977) 159.

[15] KitAigORODSKII, Molecular Crystals and Molecules (Acad. Press) 1973, p. 12

[16] Trotter, J., Acta Crystallogr. 11 (1958) 423.

[17] Robertson, J. M., White, J. G., J. Chem. Soc. (1947) 358. 